\title{
The effect of education on health: evidence from national compulsory schooling reforms
}

\author{
Raquel Fonseca $^{1,2}$ (D) Pierre-Carl Michaud ${ }^{2,3,4} \cdot$ Yuhui Zheng $^{5}$
}

Received: 9 October 2018 / Accepted: 18 July 2019 / Published online: 1 August 2019

(c) The Author(s) 2019

\begin{abstract}
This paper sheds light on the causal relationship between education and health outcomes. We combine three surveys (SHARE, HRS and ELSA) that include nationally representative samples of people aged 50 and over from fourteen OECD countries. We use variation in the timing of educational reforms across these countries as an instrument for education. Using IV-probit models, we find causal evidence that more years of education lead to better health. One additional year of schooling is associated with 6.85 percentage points (pp) reduction in reporting poor health and $3.8 \mathrm{pp}$ and $4.6 \mathrm{pp}$ reduction in having self-reported difficulties with activities of daily living (ADLs) and instrumental ADLs, respectively. The marginal effect of education on the probability of having a chronic illness is a $4.4 \mathrm{pp}$ reduction. This ranges from a reduction of 3.4 pp for heart disease to a $7 \mathrm{pp}$ reduction for arthritis. The effects are larger than those from a probit model that does not control for the endogeneity of education. However, we do not find conclusive evidence that education reduces the risk of cancer, stroke and psychiatric illness.
\end{abstract}

Keywords Education · Health · Causality · Compulsory schooling laws

JEL Classification I1 · I2

\section{Introduction}

There is abundant evidence on the relationship between education and health. ${ }^{1}$ Many studies, whether country-specific (Etile 2014; Kim 2016) or international, have docu-

\footnotetext{
${ }^{1}$ For a review, see Grossman (2005).
}

We thank Simon Lord for his excellent research assistance. This research was supported by the National Institute on Aging, under the grant R01 AG040176-06 and P01AG008291. Errors are our own.

Raquel Fonseca

fonseca.raquel@uqam.ca

Extended author information available on the last page of the article 
mented that this relationship exists in multiple countries, although magnitudes might differ (Banks et al. 2006; Andreyeva et al. 2007; Mackenbach et al. 2008; Michaud et al. 2011). These results deserve attention: if the link is causal, then the effect of education on health should be taken into account when designing education and health policies. This paper aims to estimate the causal effect of education on various health outcomes using cross-country variation in the timing of education reforms.

Many mechanisms have been suggested on how education could improve health: raising efficiency in health production (productive efficiency) (Grossman 1972), changing inputs in health production (allocative efficiency) (Grossman 2005), changing time preference (Becker and Mulligan 1997), changing behavioral patterns, e.g., smoking, obesity, preventive care (Huisman et al. 2005; Mackenbach et al. 2008; Barcellos et al. 2018); and finally, gaining more resources, e.g., higher income, occupational status, better housing, better food, better quality of care, and living environment (i.e., Case and Deaton 2005; Cutler and Lleras-Muney 2008).

However, there is a persistent problem with these studies. Observational studies examining correlations between education and health cannot be interpreted causally because education might be endogenous. First, earlier health endowments could affect both education and health later in life. Second, an unobserved variable, like time preference, genetic factors or family background, could affect both education and health. To solve this problem, we follow the line in the literature which has employed institutional changes as instruments for education, for instance, Lleras-Muney (2005), Cutler and Lleras-Muney (2006), Cutler and Lleras-Muney (2008), Clark and Royer (2013), Brunello et al. (2016) and Galama et al. (2018), among others. ${ }^{2}$ This literature has generated different results. Our goal is to add to the literature on understanding the causal effect of education on health.

We use three data sets including nationally representative samples of individuals aged 50 and over from 14 OECD countries. These are the Health and Retirement Study (HRS) for the USA, the English Longitudinal Study of Ageing (ELSA), and the Study of Health, Ageing and Retirement in Europe (SHARE). We instrument education using differences in educational reform across these countries, the hypothesis being that different compulsory schooling laws can affect education differently across birth cohorts and across countries in an exogenous way, given that the laws can change by time and/or by country. We consider compulsory schooling laws that would impact individuals born between 1905 and 1955. For eight out of the fourteen countries in our analysis, a nationwide change in compulsory schooling laws was noted for cohorts born between those years. For the other countries, there was either no such change, or the change varied geographically within a country.

We find that more years of education lead to a lower probability of self-reporting poor health (SRH) and self-reported difficulties with activities of daily living (ADLs) as well as instrumental ADLs (IADLs), and lower prevalence in chronic illness. More specifically, one additional year of schooling is associated with 6.85 percentage points (pp) reduction in reporting poor health, 4.6 and $3.8 \mathrm{pp}$ reduction in having ADL and IADL limitations. Concerning the chronic illness indicator, we document a $4.4 \mathrm{pp}$ reduction: $2.7 \mathrm{pp}$ reduction for diabetes, $3.3 \mathrm{pp}$ reduction for heart disease, $4.6 \mathrm{pp}$

\footnotetext{
${ }^{2}$ See next section for the details.
} 
reduction for hypertension, $7 \mathrm{pp}$ reduction for arthritis and $1.4 \mathrm{pp}$ for lung disease. These effects are larger and different than the probit estimates alone, which do not control for the endogeneity of education. We do not find conclusive evidence that education has a causal effect on cancer, stroke and psychiatric illness.

This paper adds to the current literature in the following ways. First, we find a causal relationship between education and health by using cross-country variation in compulsory schooling laws over time as an instrumental variable. Second, we examine a wide range of health outcomes, from SRH to functional status and instrumental functional status, and a set of chronic conditions. This differentiates our work from that of recent literature, for instance, Galama et al. (2018), who focus mainly on mortality and its two most common preventable behavioral causes, smoking and obesity, or Gathmann et al. (2015), who also focuses on mortality, or even Crespo et al. (2014), Brunello et al. (2013) and Mazzonna (2014). This also differentiates our work from that of Brunello et al. (2016), who concentrate on self-reported health and health behaviors (smoking, drinking, exercising and the body mass index) for European countries.

\section{Literature review}

In this section we review the subset of the literature which is the most relevant to our study.

One study using US data instrumented education using individual quarter of birth and family background (Adams 2002). It found a positive effect of education on selfreported health (SRH hereafter) and functional status in both OLS and IV estimates. Another study (Lleras-Muney 2005) explored state variation in compulsory education laws in the USA as instruments for education and found that each additional year of education lowers the probability of dying in the next 10 years by as much as 3.6 percentage points. Mazumder (2008), extending Lleras-Muney's analysis using different data, found even larger effects of education on health. Oreopoulos (2006), using compulsory schooling law changes as an instrument for education as well, also found a statistically significant relationship between education and SRH in the UK, in addition to a negative effect of education on physical and mental disability in the USA, while Silles (2009) found that increased schooling caused more self-reported good health and lowered probabilities of long-term illness, activity-limiting experience, and work-preventing experience. Fischer et al. (2013) also found evidence, for Sweden, suggesting that education reduces mortality. Brunello et al. (2016) also found that education caused more self-reported good health and affects health behaviors for a set of European countries.

Those results are compelling, but many studies also report mixed results. Jürges et al. (2013), for instance, finds no causal effects between education and the two biomarkers under study. Furthermore, the effect of education on SRH was positively significant only among older female cohorts, whereas it was negative among younger of women and insignificant among men regardless of age. Kemptner et al. (2010), instrumenting years of schooling using variations in the timing of the introduction of a 9th grade in West Germany, found that more schooling caused less long-term illness, less work disability and less obesity among men but not women. Smoking behavior was not 
causally affected by education in either gender. More mixed evidence is reported by van Kippersluis et al. (2011), who use Dutch data. Their estimates show that an extra year of schooling reduces the probability of dying for older men. Similarly, Gathmann et al. (2015) find that more education yields small mortality reductions in the short and long run for men, while women, in contrast, appear to experience no mortality reductions from compulsory schooling reforms. More recently, Galama et al. (2018) reviewed the evidence on education's causal effects on smoking and obesity. They found no convincing evidence of an effect of education on obesity, while the effects on smoking are not apparent when duration of schooling is increased. They become significant only when schooling reforms affect individual schooling track or their peer group. An effect of education on mortality does appear to exist in some contexts, but not in others, and seems to depend on gender, on labor market returns of education, and whether education affects the quality of an individual's peers.

Many more studies simply fail to find an association between education and health. Albouy and Lequien (2009), for example, who also instrument education using school reform, fail to find a statistically significant causal effect of education on mortality in France. Similarly for Britain, Clark and Royer (2013) find little evidence that additional schooling improves health outcomes or changes health behaviors. In Denmark, Arendt (2005) found that the IV estimates of education on SRH and body mass index (BMI) were statistically insignificant and not statistically different from those estimated using OLS.

In short, studies examining the causality between education and health have generated different results. Focusing on older populations across different countries, our goal is to shed further light on the causal effect of education on a broad set of health outcomes. Doing so, our study is perhaps closest to that of Brunello et al. (2016), who use compulsory laws as instruments in SHARE and ELSA focusing on health behaviors between men and women.

\section{Data and descriptive analysis}

\subsection{HRS, SHARE and ELSA}

We focus on individuals aged 50 and over in fourteen countries using comparable survey data: the USA, England, and twelve continental European countries. ${ }^{3}$ Our main data sources are the three longitudinal surveys on aging: the Health and Retirement Study (HRS) in the USA, the English Longitudinal Study of Ageing (ELSA) in England, and the Study of Health, Ageing and Retirement in Europe (SHARE). These surveys were specifically designed to be comparable with one another and each targeted people living in the community and aged 50 and over. Follow-up surveys were conducted biennially. We used data from wave 10 of HRS (2006), wave 3 of ELSA (2006), and wave 2 of SHARE (2006), all of which had been collected between 2006 and 2007.

\footnotetext{
3 Countries included in our study from SHARE are: Austria, Sweden, the Netherlands, Italy, France, Greece, Switzerland, Belgium, Germany, Czech Republic, Poland and Spain.
} 
All study surveys contain a large set of measures of health status, most of which are comparable across surveys. We constructed from the data a set of subjective and objective measures of health outcomes. Subjective measures for this analysis included overall self-rated health status (SRH), self-reported difficulties with activities of daily living (ADLs) as well as instrumental ADLs (IADLs). SRH was measured by asking respondents to rate their health on a five-point scale: excellent, very good, good, fair, poor. We defined a binary variable of "poor health", which takes value of 1 if the self-rated health is fair or poor and 0 otherwise. Transforming these variables in dichotomous ones preserve homogeneity of methods in terms of binary choice models. We check our results with alternative SRH cutoffs. For limitations in ADLs, questions were asked in all surveys about difficulties in five basic activities: bathing, dressing, eating, getting in and out of bed, and walking across a room. Individuals were classified as having any ADL limitation if they reported limitations with one or more of the five activities. Limitations in IADLs were measured by questions about difficulties in the following five activities: making meals, shopping, making phone calls, taking medications and managing money. Those who reported having some difficulty with any of the five activities were classified as having any IADL limitation.

Objective measures included in all surveys were the same set of doctor-diagnosed disease questions on cancer, diabetes, hypertension, heart disease, stroke, lung disease, arthritis, and psychological illness. ${ }^{4}$ We created a binary variable "any chronic" when individuals report having any of these chronic conditions. We also analyzed these variables one by one.

Our main independent variable is "years of education". In HRS, respondents were asked about the highest grade of school or year of college completed. In ELSA, the variable is defined by the age at which respondents finished full-time education. We converted the values into years of education by subtracting the age when the respondent left school by the usual school started age of five. In the second wave of SHARE, the respondents were asked directly about years of full-time education.

Other demographic variables include gender and age. In order to ascertain the robustness of our results, we also consider employment status (working versus non working), marital status (1. Married/partner 2. Divorced/separated 3. Widowed and 4. Never married), household size, and mother and father alive.

\subsubsection{Descriptive statistics}

Table 1 presents summary statistics of the data in more detail. We report the number of observations (between 51,000 and 53,700, depending on the variables), the mean responses and standard deviations, and the minimum and maximum values. $34 \%$ of the sample reported poor health, and $73 \%$ of the sample had one or more diagnosed chronic conditions. The prevalence for specific health conditions ranges from $5 \%$ for stroke and $44 \%$ for hypertension. For functional status, $13 \%$ reported having one or more ADL limitations, while $10 \%$ reported having one or more IADL limitations. Our

\footnotetext{
4 The measure of a "psychiatric illness" in SHARE is different from those in HRS and ELSA. In HRS and ELSA there is a question of "Have you ever had or has a doctor ever told you that you had any emotional, nervous, or psychiatric problems?" In SHARE the closest measure is from the question of "Has there been a time or times in your life when you suffered from symptoms of depression which lasted at least 2 weeks?"
} 
Table 1 Summary statistics

\begin{tabular}{|c|c|c|c|c|c|}
\hline Variables & Obs & Mean & SD & Min & $\operatorname{Max}$ \\
\hline \multicolumn{6}{|l|}{ Health variables } \\
\hline Poor health & 53,492 & 0.34 & 0.47 & 0 & 1 \\
\hline $1+$ chronic illness & 53,634 & 0.73 & 0.44 & 0 & 1 \\
\hline $1+\mathrm{ADLs}$ & 53,517 & 0.13 & 0.34 & 0 & 1 \\
\hline $1+$ IADLs & 53,516 & 0.10 & 0.31 & 0 & 1 \\
\hline Cancer & 53,467 & 0.08 & 0.27 & 0 & 1 \\
\hline Diabetes & 53,519 & 0.14 & 0.35 & 0 & 1 \\
\hline Heart disease & 53,518 & 0.18 & 0.39 & 0 & 1 \\
\hline Hypertension & 53,534 & 0.44 & 0.50 & 0 & 1 \\
\hline Arthritis & 53,528 & 0.36 & 0.48 & 0 & 1 \\
\hline Lung disease & 53,521 & 0.07 & 0.26 & 0 & 1 \\
\hline Stroke & 53,530 & 0.05 & 0.22 & 0 & 1 \\
\hline Psychiatric illness & 53,399 & 0.16 & 0.37 & 0 & 1 \\
\hline \multicolumn{6}{|l|}{ SES variables } \\
\hline Years of education & 52,077 & 11.00 & 3.85 & 0 & 25 \\
\hline Age & 53,634 & 66.07 & 9.73 & 50 & 89 \\
\hline Cohort & 53,634 & 3.82 & 1.95 & 1 & 8 \\
\hline Male & 53,634 & 0.45 & 0.50 & 0 & 1 \\
\hline Marital status & 51,991 & 1.55 & 0.92 & 1 & 4 \\
\hline Employment status & 53,320 & 0.30 & 0.46 & 0 & 1 \\
\hline Household size & 53,634 & 2.18 & 1.05 & 1 & 14 \\
\hline \multicolumn{6}{|l|}{ Family background } \\
\hline Mother alive & 51,966 & 0.20 & 0.40 & 0 & 1 \\
\hline Father alive & 52,073 & 0.08 & 0.27 & 0 & 1 \\
\hline
\end{tabular}

Data source: HRS wave 10, SHARE wave 2, and ELSA wave 3. Data are weighted by sampling weight (normalized by country)

key independent variable "years of education" ranges from no education to 25 years of education with a mean of 11 years with a standard deviation of 3.85. The average age of the sample is 66 years old ranging from 50 to 89 years, and $45 \%$ of respondents are male.

\subsubsection{Health and education}

Table 2 shows the unadjusted prevalence of health outcomes by education and by country. For ease of presentation, we recode years of education into three categoriestertiary, secondary, and primary or less-based on the educational system in each country. "tertiary" indicates the category with the highest level of education, while "primary" indicates the category with the lowest level of education. In the first column, we list the percentage reporting poor health. In all countries, there is a clear gradient for the relationship between education and poor health, with those in the lowest level of education reporting worse health than those in the middle category, while these 


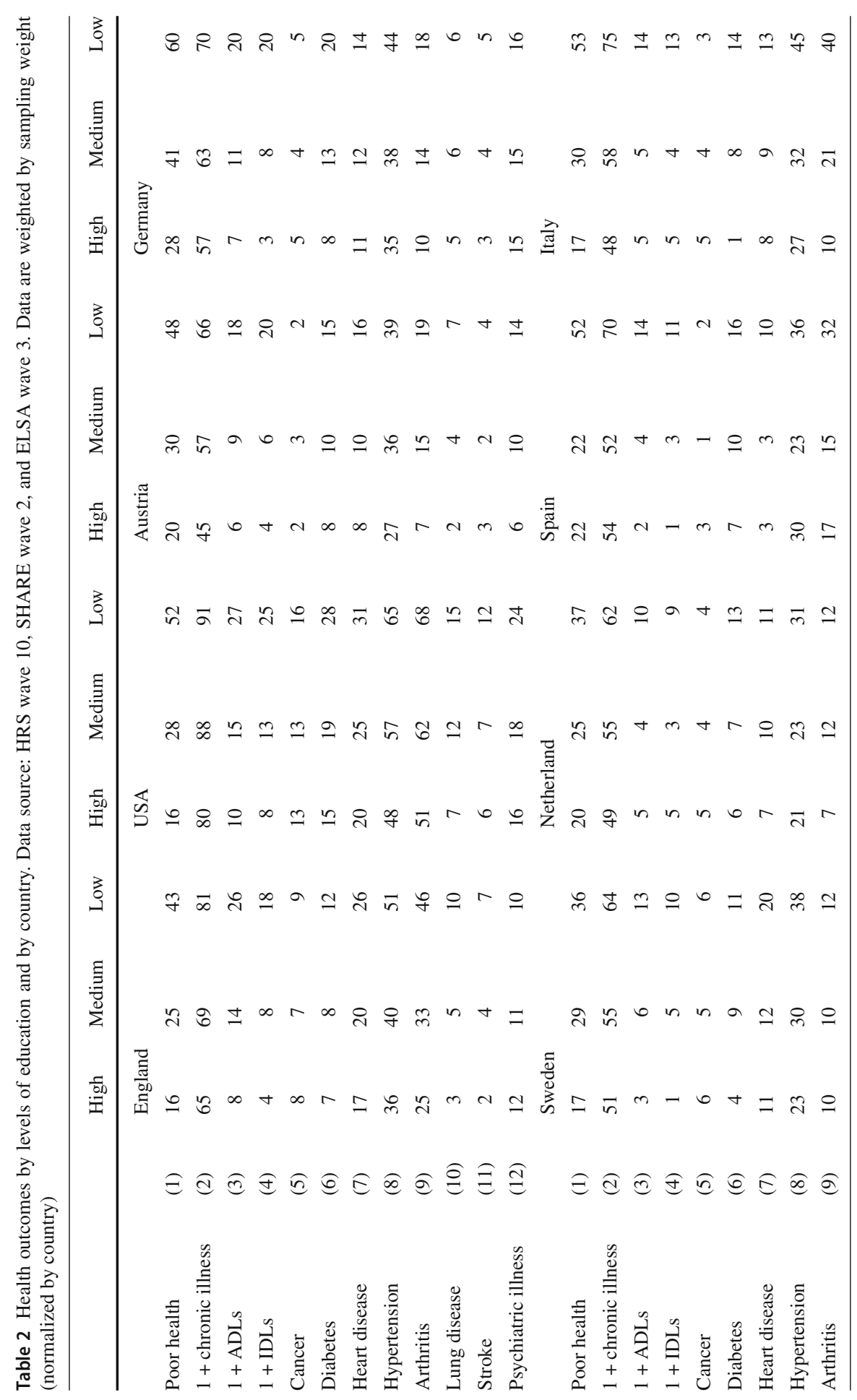




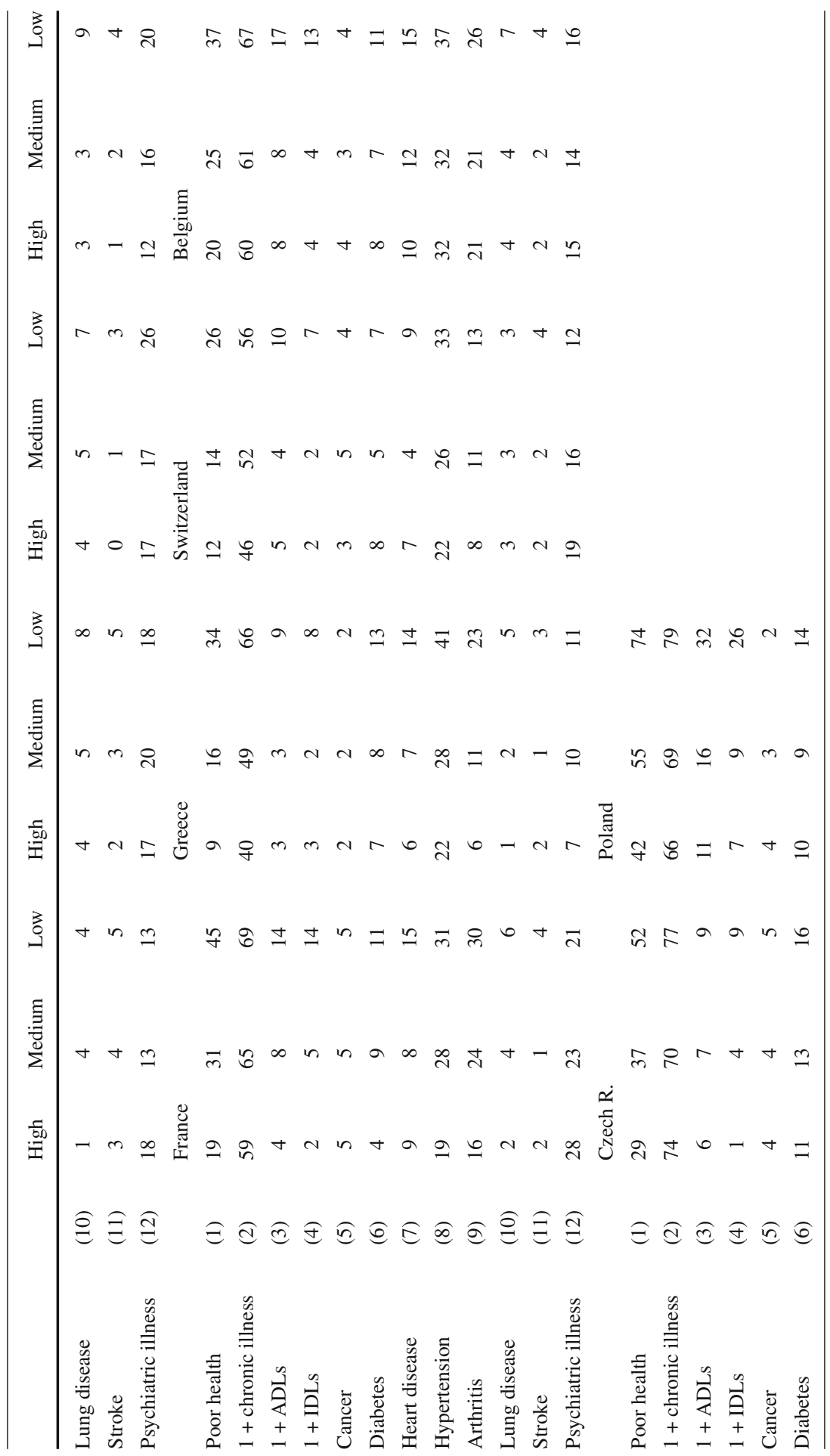




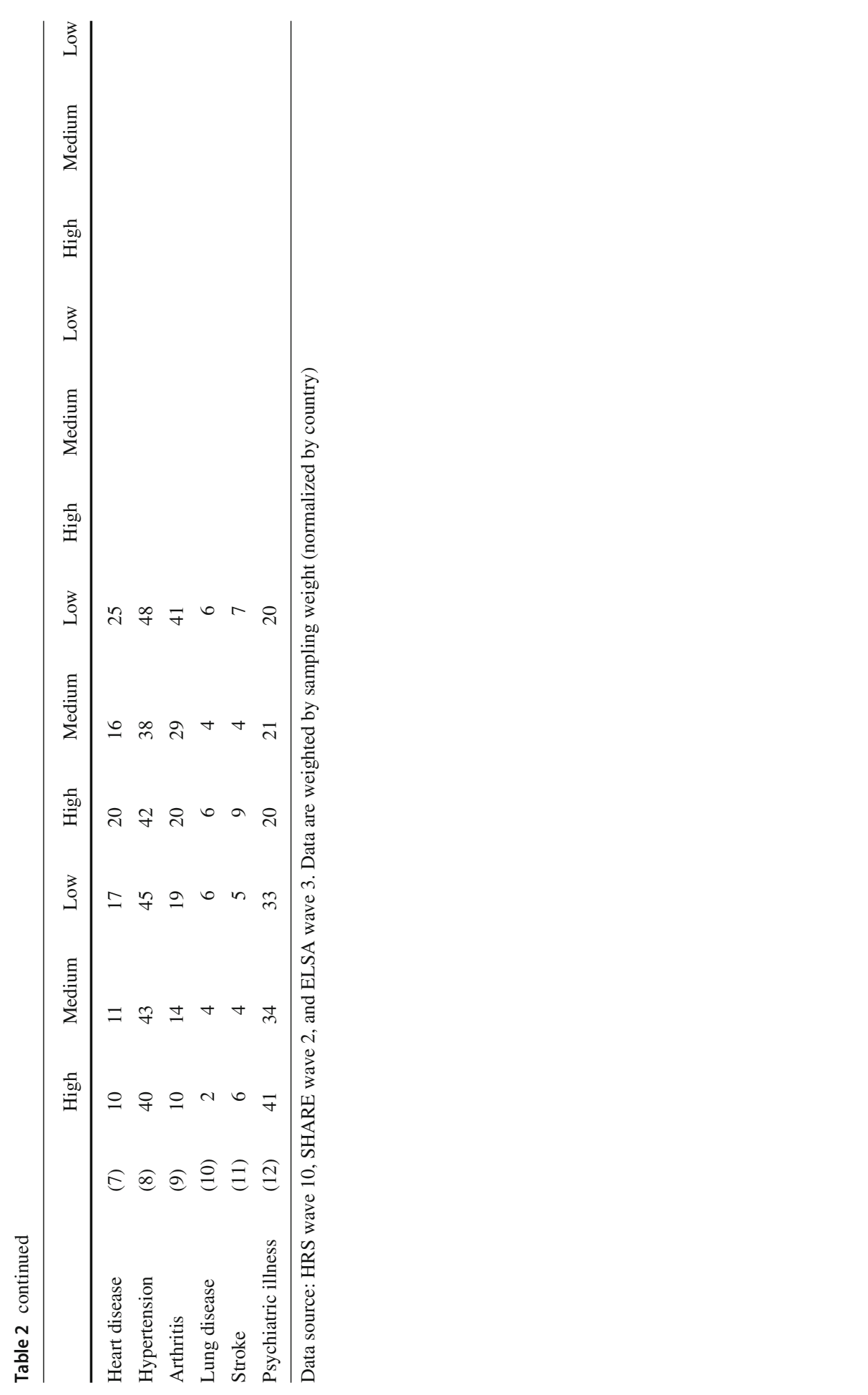


latter report worse health than those in the highest category. We are aware that selfreported health could be subject to different measurement errors (see Jürges 2007). In our empirical analysis, we will address this by controlling for countries specific effects.

The second row shows the percentage of people with any chronic condition. Americans report higher levels of chronic disease than Europeans. England, Germany, Spain, Italy, France, Poland, Czech Republic and Belgium report higher levels of chronic disease than the other European countries. Countries with larger gradients in reporting conditions by education are the USA, England, Greece, Italy, Austria, Spain, Poland and Czech Republic and Germany.

Rows 3 and 4 show the percentages of people with difficulties for I(ADLs). All countries present very high proportions of low-educated individuals with I(ADLs) difficulties compared to the middle-educated and high-educated ones. In particular, these differences are larger in England, the USA, and Poland.

In rows 5 to 12 , we show the prevalence of specific health conditions. The three most prevalent conditions are hypertension, arthritis and heart disease. Americans and English report higher percentages of cancer, arthritis and lung disease than other countries in each education category. Americans, Polish and Czech report higher percentages of diabetes in each educational category than the rest of the countries. For hypertension, arthritis, heart disease and lung disease, low-educated individuals reported higher percentages than high-educated ones in every country. For diabetes, the percentages are higher in the low-educated relative to the high-educated in twelve out of the fourteen countries, with the exception of Switzerland, in which the low-educated have a prevalence of $7 \%$ while the high-educated have a prevalence of $8 \%$. For cancer, the prevalence is higher among the high-educated, relative to that among the loweducated, for four out of the fourteen countries. For stroke, the prevalence is higher for the low-educated group relative to that of the high-educated group in all countries with the exception of Poland, where the prevalence of the low-educated is $7 \%$ while the prevalence of the high-educated is $9 \%$. Finally, the patterns of self-reported psychiatric illness by education differ by country. In England, Sweden, France, Switzerland and the Czech Republic, the higher-educated individuals report more psychiatric illness than the rest of the countries where the proportions are closer between different levels of education.

Table 3 shows the correlations between health and years of education without adjusting for other variables. Our results are in line with the literature. There is a negative correlation between poor health and years of education. All the correlation coefficients are statistically significant at the $1 \%$ level. The more educated are less likely to report poor health, any chronic condition, or any ADL or IADL limitations. One exception is the positive correlation of ever diagnosed with cancer with education. This positive correlation for cancer is consistent with other studies (e.g., Smith 2004; Cutler and Lleras-Muney 2008). Possible explanations are that more educated people are more likely to visit the doctors and are diagnosed earlier, survive longer, or have specific risk factors related to years of education, like late childbearing among women. The correlation between self-reported health and years of education is stronger than the relationships between education and other outcomes. 
Table 3 Correlation coefficients of years of education and health outcomes

\begin{tabular}{llllllr}
\hline Poor health & $1+$ Chronic illness & \multicolumn{2}{c}{$1+$ ADLs } & $1+$ IADLs & Cancer & Diabetes \\
\hline-0.248 & -0.040 & -0.114 & -0.122 & 0.066 & -0.056 \\
\hline Heart disease & Hypertension & Arthritis & Lung disease & Stroke & Psychiatric illness \\
\hline-0.027 & -0.038 & -0.007 & -0.047 & -0.017 & -0.020 & \\
\hline
\end{tabular}

All Spearman correlations are significant at $1 \%$. Data source: HRS wave 10, SHARE wave 2, and ELSA wave 3 . Data are weighted by sampling weight (normalized by country)

\subsection{Compulsory schooling laws and Education}

To examine the causal relationship between education and health, we use the crosscountry variation in compulsory schooling laws over time as instruments for years of education. Our hypothesis is that different compulsory schooling laws can affect education differently across birth cohorts and across countries in an exogenous way, given that the laws can change by time and/or by country. Since individuals in our sample are aged 50 years and older, we consider compulsory schooling laws that would impact individuals born between year 1905 and year 1955. For eight out of the fourteen countries in our analysis, there was a nationwide change in compulsory schooling law for cohorts born between 1905 and 1955. For the other countries there was either no such law change or the change varied geographically within a country. We obtain the information from different data sources. In England, the 1944 Education Act raised the minimum school leaving age from 14 to 15, for cohorts born in Apr 1933 or later (Oreopoulos 2006; Jürges et al. 2013; Silles 2009); In France, minimum school leaving age was raised from 13 to 14 for those born after 1923 (Albouy and Lequien 2009); Information on compulsory schooling and reforms for Austria, Greece, Italy, Netherlands and Sweden was obtained from a paper by Murtin and Viarengo (2007). Finally, in Czech Republic the compulsory schooling age was 8 years from 1869. With the education reform in 1948, the compulsory schooling age was increased to 9 years (Filer et al. 1999). Five other countries are assumed to have no compulsory schooling law changes that would affect the birth cohorts from 1905 to 1955. For Switzerland, Belgium and Spain, the documented compulsory education reforms took place in 1970 or later and did not affect cohorts in our sample. The compulsory education reform for Poland was in the 1960's, only affecting a small subset of our sample. For Germany and USA, education reforms varied across geographic areas within the country and we are not able to define a beginning date for a nationwide reform in compulsory schooling law.

Table 4 reports the average years of education by country, for those aged 50 and over using our sample. The table also shows the years of compulsory attendance required before and after compulsory schooling law changes for each country, as well as the first birth cohort that were subject to compulsory schooling law changes. The average years of education for aged 50 and over are lowest in Spain (7.41 years), and highest in the USA (12.85 years). 


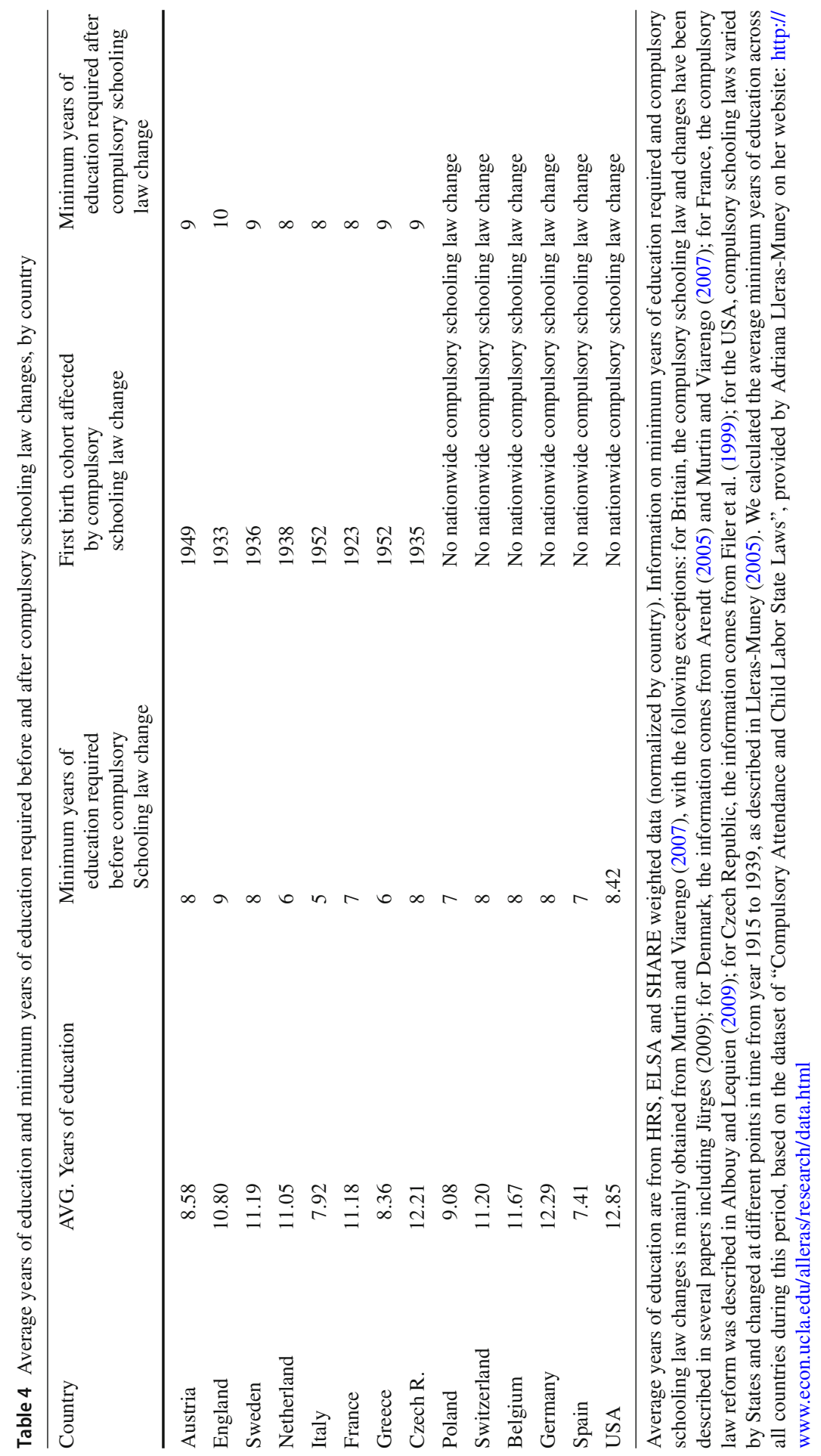



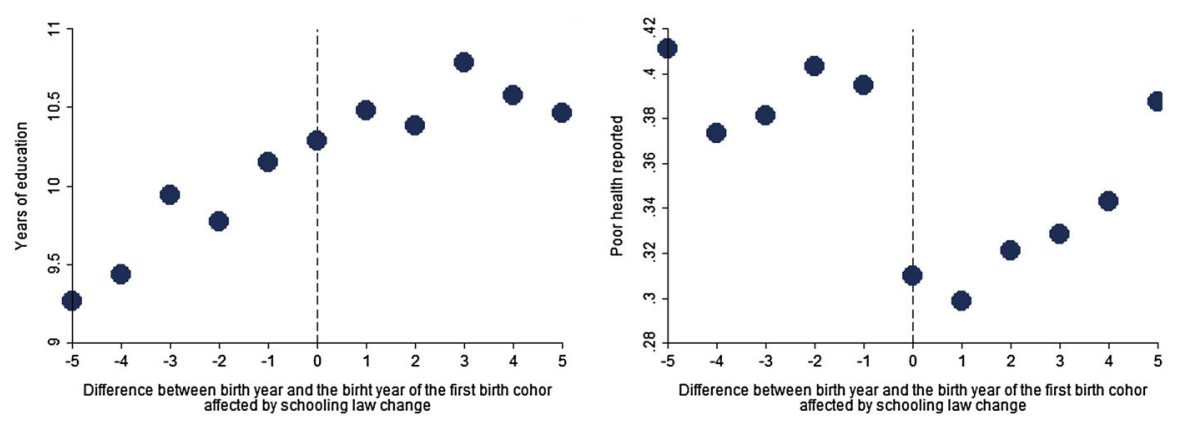

Fig. 1 Adjusted proportion of years of education (left) and reporting poor health (right) by birth cohorts. Average proportion of reporting poor health is based a probit regression of self-reported poor health against gender, birth cohort dummies, country dummies. The sample includes individuals born 5 years before and after the birth cohort affected by schooling law change. Data source: HRS wave 10, ELSA wave 3, SHARE wave 2. Data weighted by sampling weight

In Fig. 1, we draw the reduced-form relationship between compulsory schooling law changes and both, years of education and one of the health outcomes, i.e., poor health. We pool the data from the eight countries with law changes and calculate the proportion of years of education (left graph) and the reporting poor health (right graph) by birth cohort, for individuals born 5 years before and after the first cohort affected by law changes, adjusting for gender, cohort and country. There is a sharp reduction in the proportion reporting poor health for the cohorts affected after the year of reform and the downward shift persists after that year, increasing slightly after the second cohort.

\section{Empirical strategy}

We first model the effect of education on different health outcomes using a probit model. $H_{j, i}$ indicates health outcome $j$, a binary measure, for an individual $i, H_{j, i}$ takes the value of 1 if the underlying latent variable, $H_{j, i}^{*}$, is positive and zero otherwise. $E d_{i}$ represents education for the individual, measured as years of education obtained. $X_{i}$ contains a set of demographic variables: gender, birth cohort dummies for nine age groups, and country. One could control for other characteristics such as income and marital status, but then we run the risk of over-controlling as education reforms might impact these outcomes as well which will then impact health. Pooling the three data sets, we estimate the latent variable $H_{j, i}^{*}$ for all health outcomes. For example, we estimate the probability that an individual is in "poor health" or the probability that an individual has any chronic disease using the following model:

$$
\begin{aligned}
& H_{j, i}^{*}=\alpha_{j}+E d_{i} \beta_{j}+X_{i} \gamma_{j}+\varepsilon_{j} \\
& H_{j, i}=I\left(H_{j, i}^{*} \geq 0\right)
\end{aligned}
$$

where $\varepsilon_{j}$ is a random error that is normally distributed. 
However, we know that education can be endogenous. As mentioned in the introduction, different factors can drive this endogeneity, such as reverse causality or unobserved heterogeneity. This potential endogeneity can be addressed with an instrumental variable probit model in a two-equation model. The set of equations (2) is equivalent to the estimation (1) above. In equation (3), we model education as a function of a set of control variables, $X_{i}$, as well as $Z_{i}$, which is the minimum years of education required for a given individual and varies by country and birth cohort.

$$
\begin{aligned}
H_{j, i}^{*} & =\alpha_{j}+E d_{i} \beta_{j}+X_{i} \gamma_{j}+\varepsilon_{j} \\
H_{j, i} & =I\left(H_{j, i}^{*} \geq 0\right) \\
E d_{i} & =\theta+X_{i} \lambda+Z_{i} \phi+v_{j}
\end{aligned}
$$

$\varepsilon_{j}, v_{j}$ are random errors that are normally distributed. The key coefficient of interest is $\beta_{j}$. If education is exogenous, the probit estimation of Eq. (1) generates an unbiased estimation of $\beta_{j}$. However, education might be endogenous. We therefore use an instrumental variable approach to estimate $\beta_{j}$. The variable, $Z_{i}$ minimum years of education required, is the instrument. Since we control for gender, country dummies, and birth cohort in both stages of the model, the effect of $Z_{i}$ on $E d_{i}$ is estimated after taking into account the country- and cohort-specific effects. $Z_{i}$ should not affect health outcomes other than through its effect on years of education. This cannot be directly tested as we only have one instrument. However, it is a reasonable assumption if there were no co-occurrence factors that affected both compulsory schooling law changes and health. The use of compulsory school law changes from multiple countries reduces the possibility of such co-occurrence. Our empirical strategy is very similar to the one that Lleras-Muney (2005) does for USA. We use the compulsory schooling minimum age laws across different countries, and we analyze the effects of these changes on education and different health outcomes. We study the across-country variability in outcomes by comparing countries where reforms were implemented compared to other countries where no reform was implemented. These latter countries serve as control groups. We cluster the standard errors at the birth year-country level.

We then first estimate a probit model based on Eq. (1) for each health outcome. For the instrumental variable approach, we jointly estimate (2) and (3) using maximum likelihood and assume $\varepsilon_{j}, v_{j}$ are multivariate normal with correlation coefficient $\rho_{j}$. We then test whether $\rho_{j}$ is statistically different from zero to see whether the education variable is exogenous or if the multivariate probit model estimates based on (1) is appropriate. Probit and IV-probit models are estimated using the "probit" and "ivprobit" commands in Stata.

\section{Results}

\subsection{Health and education across countries}

We first estimate model (1) to replicate this evidence across countries and using HRS, ELSA and SHARE data sets. The main results are reported in Table 5 for different 
Table 5 Probit models of years of education on health outcomes (coefficients reported as marginal effects)

\begin{tabular}{|c|c|c|c|c|}
\hline & Poor health & $1+$ Chronic illness & $1+\mathrm{ADLs}$ & 1+IADLs \\
\hline \multirow[t]{2}{*}{ Years of education } & $-0.0285^{* * *}$ & $-0.0063 * * *$ & $-0.0110 * * *$ & $-0.0098 * * *$ \\
\hline & $(0.0012)$ & $(0.0007)$ & $(0.0005)$ & $(0.0004)$ \\
\hline$N$ & 51,955 & 52,077 & 51,998 & 51,997 \\
\hline \multirow[t]{2}{*}{ Mean } & 0.3353 & 0.7295 & 0.1338 & 0.1049 \\
\hline & Cancer & Diabetes & Heart disease & Hypertension \\
\hline \multirow[t]{2}{*}{ Years of education } & $0.0032 * * *$ & $-0.0064 * * *$ & $-0.0048 * * *$ & $-0.007 * * *$ \\
\hline & $(0.0003)$ & $(0.0006)$ & $(0.0004)$ & $(0.0008)$ \\
\hline$N$ & 51,952 & 52,002 & 52,001 & 52,017 \\
\hline \multirow[t]{2}{*}{ Mean } & 0.0803 & 0.1389 & 0.1849 & 0.4414 \\
\hline & Arthritis & Lung disease & Stroke & Psychiatric illness \\
\hline \multirow[t]{2}{*}{ Years of education } & $-0.0098 * * *$ & $-0.0045^{* * *}$ & $-0.0010 * * *$ & $-0.0020 * * *$ \\
\hline & $(0.0009)$ & $(0.0004)$ & $(0.0002)$ & $(0.0007)$ \\
\hline$N$ & 52,012 & 52,005 & 52,014 & 51,898 \\
\hline Mean & 0.3645 & 0.0722 & 0.0522 & 0.1650 \\
\hline
\end{tabular}

Robust standard errors in parentheses, clustered at birth year-country level. All models control for gender, cohort dummies, and country dummies. Data source: HRS wave 10, SHARE wave 2, and ELSA wave 3. Data are weighted by sampling weight (normalized by country)

$* * * p<0.01, * * p<0.05, * p<0.1$

health outcomes. The table provides the marginal effects of years of education on health. The coefficients are all negative and significant at the $1 \%$ level, meaning that more education is associated with lower probability of having health problems. The only exception is cancer, for which the coefficient is positive and significant, as noted in the unadjusted results. For SRH, each additional year of schooling is associated with a 3 pp reduction in reporting poor health. Each additional year of schooling is also associated with a $1.1 \mathrm{pp}$ reduction in having ADL and $1 \mathrm{pp}$ reduction in having IADL limitations. As for chronic conditions, the marginal effects are smaller and range from $1 \mathrm{pp}$ reduction for arthritis to $0.2 \mathrm{pp}$ reduction for psychiatric illness. There is a $0.3 \mathrm{pp}$ increase in the incidence of cancer. All models control for gender, country, and birth cohort. In addition, country dummies are included in all specifications to account for institutional and cultural differences. The complete tables are available from the authors upon request.

\subsubsection{Causal relationship between health and education}

We next turn to instrumental variable estimation to examine the effects of education and health.

The first-stage estimation is a linear regression of the individual's years of education against minimum years of education required by compulsory schooling laws, controlling for gender, birth cohort, and country. The estimate is statistically significant at 
Table 6 First-stage results

\begin{tabular}{lc}
\hline & Years of education \\
\hline Minimum years of schooling required & $0.5623^{* * *}$ \\
\hline $\begin{array}{l}\text { First-stage results for minimum years of schooling required are equal across health outcomes. Robust } \\
\text { standard errors in parentheses, clustered at birth year-country level. All models control for gender, cohort } \\
\text { dummies, and country dummies. Data source: HRS wave 10, SHARE wave 2, and ELSA wave 3. Data are } \\
\text { weighted by sampling weight (normalized by country) }\end{array}$
\end{tabular}
$* * * p<0.01, * * p<0.05, * p<0.1$

Table 7 IV-Probit models of years of education on health outcomes (coefficients reported as marginal effects)

\begin{tabular}{|c|c|c|c|c|}
\hline & Poor health & $1+$ Chronic illness & $1+\mathrm{ADLs}$ & $1+\mathrm{IADLs}$ \\
\hline \multirow[t]{2}{*}{ Years of education } & $-0.0685^{* * *}$ & $-0.0442 * * *$ & $-0.0385^{* * *}$ & $-0.0460 * * *$ \\
\hline & $(0.0038)$ & $(0.0073)$ & $(0.0067)$ & $(0.0075)$ \\
\hline$N$ & 51,955 & 52,077 & 51,998 & 51,997 \\
\hline \multirow[t]{2}{*}{ Mean } & 0.3353 & 0.7295 & 0.1338 & 0.1049 \\
\hline & Cancer & Diabetes & Heart disease & Hypertension \\
\hline \multirow[t]{2}{*}{ Years of education } & 0.0024 & $-0.0274 * * *$ & $-0.0338 * * *$ & $-0.0464 * * *$ \\
\hline & $(0.0058)$ & $(0.0085)$ & $(0.0071)$ & $(0.0077)$ \\
\hline$N$ & 51,952 & 52,002 & 52,001 & 52,017 \\
\hline \multirow[t]{2}{*}{ Mean } & 0.0803 & 0.1389 & 0.1849 & 0.4414 \\
\hline & Arthritis & Lung disease & Stroke & Psychiatric illness \\
\hline \multirow[t]{2}{*}{ Years of education } & $-0.0703 * * *$ & $-0.0139 * *$ & -0.0070 & 0.0000 \\
\hline & $(0.0044)$ & $(0.0060)$ & $(0.0051)$ & $(0.0089)$ \\
\hline$N$ & 52,012 & 52,005 & 52,014 & 51,898 \\
\hline Mean & 0.3645 & 0.0722 & 0.0522 & 0.1650 \\
\hline
\end{tabular}

Robust standard errors in parentheses, clustered at birth year-country level. All models control for gender, cohort dummies, and country dummies. Data source: HRS wave 10, SHARE wave 2, and ELSA wave 3. Data are weighted by sampling weight (normalized by country)

$* * * p<0.01, * * p<0.05, * p<0.1$

the $1 \%$ level. Raising minimum years required of education by one year increased the average years of education by 0.56 years (around 6.4 months) (see Table 6).

Table 7 shows second-stage estimations for each of the binary health outcomes. Marginal effects and robust standard errors are displayed. The second-stage estimation is a probit model of a health outcome against years of education, gender, birth cohort, and country. The results are mixed for the second-stage estimates. For nine of the twelve health outcomes, i.e., poor health, any chronic illness, ADL, IADLs, diabetes, heart disease, hypertension and arthritis lung disease, the effect of education remains negative. The coefficients are all significant at the $1 \%$ level, except for lung disease, which is significant at the 5\% level and cancer, stroke and psychiatric illness which are no longer significant. The magnitudes of the point estimates are much larger when using 
IV estimation, as compared to the previous model. For example, the marginal effect of education on the probability of reporting poor health increases from 2.8 to $6.85 \mathrm{pp}$ and both ADL and iADLs functional status indicators increase from 1 percentage point to 3.8 and 4.6 percentage points, respectively, which represent non-negligible effects.

The magnitudes of point estimates are much larger for most of the chronic illnesses using IV estimation. For example, the marginal effect of education on the probability of having any chronic illness increases from 0.6 percentage points to 4.4 percentage points, with an average of $72 \%$ of individuals with at least one health condition in our sample. In particular, the IV marginal effects increase in magnitude compared to probit estimates as follows: for heart disease, from 0.5 percentage points reduction to 3.4 percentage points, for hypertension from 0.7 percentage points to 4.6 percentage points and for arthritis from 1 percentage point to 7 percentage points. Approximately $44 \%$ and $36 \%$ of individuals are ever diagnosed with hypertension and arthritis, respectively. For the remaining outcomes, the marginal effects of education decrease by 0.7 percentage points the prevalence of diabetes and by 1.4 percentage points for the prevalence of lung disease. For the other three outcomes, namely cancer, stroke and psychiatric illness, the coefficients are also larger than using the probit regressions, however, the effects are no longer significant. For these latter three outcomes, we cannot reject the probit estimates. Hence, we do not find conclusive evidence that education reduces the risk of these conditions. For cancer, this can potentially be explained by higher and earlier detection rates among cancer patients (Cutler and Lleras-Muney 2008).

It is not uncommon that IV estimates are larger, probably due to heterogeneous treatment effects or measurement errors in reported years of education (Card 2001). In the first case, the set of individual who responds to compulsory schooling laws might be different and have a different health profile (higher risk) than those who do not respond. Their health outcomes may be more sensitive to an increase in education.

\subsection{Robustness}

We replicate our analysis with different specifications for age, using age and quadratic age instead of birth cohort dummies.

Given that we use a sample of older respondents, it is possible that part of the causal effect of education is to improve survival which could lead to selection in terms of who survives to be included in the sample. As a robustness check, we perform the analysis after restricting our sample to individuals in lower age ranges. We restrict the sample to ages 50-66 and 50-70, and the results are qualitatively similar. We also control for additional socioeconomic variables as we described in Sect.3.1, including employment status, marital status, and household size. The coefficients are a bit smaller in magnitude but qualitatively similar.

In another set of regressions, we control for whether parents are alive at the interview in both the probit and IV-probit models. The rationale is that parent survival reflects family background and genetic factors, which could be correlated with both education and health. The results for the probit and IV-probit models are qualitatively unchanged.

We perform additional checks. The results are robust to including two instruments by adding the minimum compulsory schooling age quadratic. We also perform regres- 
sions using linear probability models with compulsory schooling laws as instruments. All estimates are again qualitatively unchanged. The results with different cutoffs for self-reported health yield very similar results.

We also extend our analysis to other health behaviors, such as ever smoking, currently smoking and obesity. Probit and OLS regressions for smoking measures show a positive and significant relationship with years of education. For obesity, this relationship was negative. However, the IV-probits and the linear probability models with compulsory schooling laws as instrument are no longer statistically significant. Therefore, we cannot make any statement about a causal relationship between health behavior and education. This can be due to the mature and elderly sample, e.g., social smoking has a different stigma in present times compared to some decades ago, when both educated and non-educated people used to smoke. Our results for behavioral outcomes are consistent with cited previous literature that did not find significant evidence of causality in behavioral outcomes.

Finally, some studies suggest that the effect of education on health could depend on the welfare system of the countries (i.e., Cesarini et al. 2016). We attempted to estimate effects on groups of countries with similar welfare systems to see whether causal effects of education on health varied. We defined "Northern Europe" to include Sweden and the Netherlands. "Western Europe" includes Austria, Germany, France, and Belgium. "Southern Europe" groups Spain, Italy, and Greece. "Eastern Europe" includes Czech Republic and Poland. The USA and England represent the "AngloSaxon" countries. This classification of countries broadly follows prior work, such as Ferrera (1996), and Esping-Andersen (1990, 1999). We did not find statistically different causal effects across group of countries and results were generally imprecise due to the small group of countries by subsets.

\section{Conclusion}

This paper studies the causal relationship between health outcomes and education. We combine three surveys that include nationally representative samples of individuals aged 50 and over from fourteen OECD countries. We use differences in educational reforms across these countries as an instrument for education. In particular, we consider educational reforms which changed the compulsory number of years of schooling. We found that an increase in years of education leads to lower probabilities of reporting poor health and functional status (ADL and iADLs). The causal relationship between education and several other chronic conditions, i.e., diabetes, heart disease, hypertension, arthritis, lung disease, and the probability of having at least a chronic illness is still statistically significant and larger than the probit estimates. Although the iv-probit estimates are larger for all health outcomes compared to the probit estimates, we do not find conclusive evidence that education has a significant effect on cancer, stroke and psychiatric illness.

Magnitudes are substantial. We find that an increase in compulsory schooling years of one year reduces the probability of reporting poor health by 6.85 percentage points. The marginal effects of education on ADL and ADLs functional status are a reduction of 3.8 and, respectively, 4.6 percentage points. The marginal effect of education on the 
probability of having any chronic illness is a decrease of 4.4 percentage points. These effects suggest that increasing compulsory schooling age had large benefits in terms of health. This would suggest that health benefits from higher education may justify the cost of interventions aimed at improving the quantity and quality of education in countries that have weaker compulsory schooling laws.

Open Access This article is distributed under the terms of the Creative Commons Attribution 4.0 International License (http://creativecommons.org/licenses/by/4.0/), which permits unrestricted use, distribution, and reproduction in any medium, provided you give appropriate credit to the original author(s) and the source, provide a link to the Creative Commons license, and indicate if changes were made.

\section{References}

Adams SJ (2002) Educational attainment and health: evidence from a sample of older adults. Educ Econ 10(1):97-109

Albouy V, Lequien L (2009) Does compulsory education lower mortality? J Health Econ 28(1):155-168

Andreyeva T, Michaud PC, van Soest A (2007) Obesity and Health in Europeans aged 50 years and older. Public Health 121:497-509

Arendt JN (2005) Does education cause better health? A panel data analysis using school reforms for identification. Econ Educ Rev 24(2):149-160

Banks J, Marmot M, Oldfield Z, Smith JP (2006) Disease and disadvantage in the United States and in Britain. JAMA 295(17):2037-2045

Barcellos S, Carvalho L, Turley P (2018) Education can reduce health disparities related to genetic risk of obsesity: evidence from a British Reform. Proc Natl Acad Sci (PNAS) 115(42)

Becker GS, Mulligan CB (1997) The endogenous determination of time preference. Q J Econ 112(3):729_ 758

Brunello G, Fabbri D, Fort M (2013) The causal effect of education on body mass: evidence from Europe. J Labor Econ 31(1):195-223

Brunello G, Fort M, Schneeweis N, Winter-Ebmer R (2016) The causal effect of education on health: what is the role of health behaviors? Health Econ 25(3):314-336

Card D (2001) Estimating the return to schooling: progress on some persistent econometric problems. Econometrica 69(5):1127-1160

Case D, Deaton A (2005) Broken down by work and sex: how our health declines. In: Wise DA (ed) Analysis in the economic of aging. The University of Chicago Press, Chicago, pp 185-212

Cesarini D, Lindqvist E, Östling R, Wallace B (2016) Wealth, health, and child development: evidence from administrative data on swedish lottery players. Q J Econ 131(2):687-738

Clark D, Royer H (2013) The effect of education on adult health and mortality: evidence from Britain. Am Econ Rev 103:2087-2120

Crespo L, Lopez-Noval B, Mira P (2014) Compulsory schooling, education, depression and memory: new evidence from SHARELIFE. Econ Educ Rev 43:36-46

Cutler DM, Lleras-Muney A (2006) Education and health: evaluating theories and evidence, National Bureau of Economic Research, Inc, NBER working papers: 12352

Cutler DM, Lleras-Muney A, Vogl T (2008) Socioeconomic status and heatlh: dimensions and mechanisms, National Bureau of Economic Research, Inc, NBER working papers: 14333

Esping-Andersen G (1999) Three worlds of welfare capitalism. Social foundations of post- industrial economies. Policy Press, Oxford University Press,Oxford

Esping-Andersen G (1990) Social foundations of postindustrial economies. OUP Oxford, Oxford

Etile F (2014) Education policies and health inequalities: evidence from changes in the distribution of Body Mass Index in France, 1981-2003. Econ Hum Biol 13:46-65

Ferrera M (1996) The southern model of welfare in social Europe? J Eur Soc Policy 6(1):17-37

Filer RK, Jurajda S, Planovsky J (1999) Education and wages in the Czech and Slovak Republics during transition. Labour Econ 6(1999):581-593 
Fischer M, Karlsson M, Nilsson T (2013) Effects of compulsory schooling on mortality: evidence from Sweden. Int J Environ Res Public Health 10(8):3596-3618

Galama T, Lleras-Muney A, van Kippersluis, H (2018) The Effect of education on health and mortality: a review of experimental and quasi-experimental evidence, National Bureau of Economic Research, Inc, NBER working papers: 24225

Gathmann C, Jürges H, Reinhold S (2015) Compulsory schooling reforms, education and mortality in twentieth century Europe. Soc Sci Med 127:74-82

Grossman M (1972) On the concept of health capital and the demand for health. J Polit Econ 80(2):223-255

Grossman M (2005) Education and nonmarket outcomes, National Bureau of Economic Research, Inc, NBER working papers: 11582

Huisman M, Kunst AE, Mackenbach JP (2005) Educational Inequalities in smoking among men and women aged 16 years and older in 11 European countries. Tobacco Control 14:106-13

Jürges H (2007) True health vs response styles: exploring cross-country differences in self-reported health. Health Econ 16(2):163-178

Jürges H, Kruk E, Reinhold S (2013) The effect of compulsory schooling on health-evidence from biomarkers. J Popul Econ 26(2):645-672

Kemptner D, Jürges H, Reinhold S (2010) Changes in compulsory schooling and the causal effect of education on health: evidence from Germany, MEA Working Papers, 200-2010

Kim YJ (2016) The long-run effect of education on obesity in the US. Econ Hum Biol 21:100-109

Lleras-Muney A (2005) The relationship between education and adult mortality in the United States. Rev Econo Stud 72(1):189-221

Mackenbach JP, Stirbu I, Roskam AJ, Schaap MM, Menvielle G, Leinsalu M, Kunst AE (2008) Socioeconomic inequalities in health in 22 European countries. N Engl J Med 358(23):2468-2481

Mazumder B (2008) Does education improve health? A reexamination of the evidence from compulsory schooling laws. Econ Perspect 33(2):216

Mazzonna F (2014) The long lasting effects of education on old age health: evidence of gender differences. Soc Sci Med 101:129-138

Michaud PC, Goldman D, Lakdawalla D, Gailey A, Zheng Y (2011) Differences in health between americans and western Europeans: effects on longevity and public finance. Soc Sci Med 73(2):254-263

Murtin F, Viarengo M (2007) The convergence process of compulsory schooling in Western Europe: 19502000. PSE working papers

Oreopoulos P (2006) Estimating average and local average treatment effects of education when compulsory schooling laws really matter. Am Econ Rev 96(1):152-175

Silles MA (2009) The causal effect of education on health: evidence from the United Kingdom. Econ Educ Rev 28(1):122-128

Smith JA (2004) Unraveling the SES: Health connection. Population and development review. Vol. 30, supplement: aging. Health, and Public Policy 2004:108-132

van Kippersluis H, O’Donnell O, Van Doorslaer E (2011) Long run returns to education. Does schooling lead to an extended old age? J Hum Resour 46(4):695-721

Publisher's Note Springer Nature remains neutral with regard to jurisdictional claims in published maps and institutional affiliations. 


\section{Affiliations}

\section{Raquel Fonseca $^{1,2}$ (1) $\cdot$ Pierre-Carl Michaud ${ }^{2,3,4} \cdot$ Yuhui Zheng ${ }^{5}$}

Pierre-Carl Michaud

pierre-carl.michaud@hec.ca

Yuhui Zheng

yuhuizheng1@gmail.com

1 ESG UQAM Montreal Canada Centene Corporation, Los Angeles, USA

2 CIRANO, Montreal, Canada

3 HEC Montreal, Montreal, Canada

4 NBER, Cambridge, USA

5 Centene Corporation, St. Louis, USA 